\title{
Quantitative Approaches in Coalition Foreign Policy: Scope, Content, Process
}

\author{
Sibel Oktay ${ }^{1}$, Ryan Beasley ${ }^{2}$ \\ ${ }^{1}$ University of Illinois at Springfield, USA \\ ${ }^{2}$ University of St Andrews, UK
}

Contribution to Symposium in 'European Political Science' 


\section{QUANTITATIVE APPROACHES IN COALITION FOREIGN POLICY: SCOPE, CONTENT, PROCESS}

\section{INTRODUCTION:}

From Britain to Israel, coalitions have been observed more frequently as the form of executive power across a broad range of parliamentary systems. Consequently, they have become the loci of foreign policy decisions. As this symposium demonstrates, the literature on coalition foreign policy has theorized that coalition parties shape foreign policy debates by way of their ideological positions as well as their relative size in the parliament and in the government. The quantitative study of coalition foreign policy offers to refine and test these expectations on the content of policy and its behavioral characteristics. Do coalitions constrain international commitments or do they enable extreme behavior at the international level? Are some coalitions more constraining or enabling than others, and which mechanisms explain those relationships? Does the ideological cohesion of coalition parties alleviate constraints? How does the relative ideological positioning of coalition parties influence foreign policy choices? This symposium contribution presents an overview of the quantitative literature on coalition foreign policy that has grown at a remarkable speed over the last decade to respond to these puzzles among others.

These studies have not only dissected coalition governments to highlight the effects of their arithmetic and ideological setup on foreign policy behaviour, but situated the empirical analyses within frameworks ranging from coalition theories in Comparative Politics to theories of group psychology. In so doing, they have been successful in realising Foreign Policy Analysis "as a bridging field linking international relations theory, comparative politics and the foreign 
policymaking community" (Hudson and Vore, 1995: 228). These studies have also moved away from the context of conflict behaviour in International Relations, which provides only a subset of all international interactions, towards a more inclusive scope. Indeed, empirical tools such as events data have allowed for the comprehensive analysis of the cooperative as well as the conflictual behaviour of coalition governments, and may open further avenues in examining the wide variety of state behaviours in the international system.

The remaining sections of this article survey the emergence and development of this literature, its debates, contributions, limitations, and possible avenues for further research. We begin by presenting the motivations behind the coalition foreign policy research agenda and its contributions by situating it vis-à-vis the previous generation of scholarship that focused on the effects of domestic politics on the international conflict behaviour of democracies. The third section discusses the explanandum (Hudson, 2014) in coalition foreign policy. What is the nature of coalition foreign policy behaviour: is it more cooperative, conflictual, or generally more extreme or committed? Furthermore, what other types of measures can we develop? In the fourth section, we unpack the substantive contributions of the coalition foreign policy literature by introducing its 'content'- and 'process'-based approaches, specifically with regards to the role that the ideological composition and size of coalitions play in explaining behaviour. In the final section, we discuss the role of context and the promise of multi-method approaches for future research on coalition foreign policy. We conclude that complementing aggregate-level analyses with nuanced and more targeted case study designs will help us move closer to a real research program that links Foreign Policy Analysis with International Relations. Further, studying the quality of foreign policy-making will bring our research closer to the Comparative Politics 
literature on coalitions, thus providing the field a more complete picture of how this government type works.

\section{BRINGING 'FOREIGN POLICY' BACK IN: EXPLICATING THE LINK BETWEEN DOMESTIC POLITICS AND INTERNATIONAL BEHAVIOUR}

Although the theoretical significance of coalitions on foreign policy-making has been discussed for quite some time (Hagan, 1993; Hagan, Everts, Fukui and Stempel, 2001), the quantitative literature on the subject has emerged first as a response to what we call 'the first generation' studies on domestic politics and international conflict.

The prominence of the 'Democratic Peace' literature by the late-1990s paved the way for the first generation studies: if "the use of force by democracies in large part results from the domestic circumstances confronting their chief executives" (Auerswald, 1999: 469), how could we explicate the domestic institutions that have led to those circumstances? Could we operationalise the domestic political institutions of democracies and test their influence on their international behaviour? In a number of influential contributions Prins and Sprecher (1999), Ireland and Gartner (2001), Reiter and Tillman (2002), Leeds and Davis (1997, 1999), Leblang and Chan (2003) and Palmer, London, and Regan (2004) have answered these puzzles with sophisticated quantitative analyses.

These studies have scrutinised democratic institutions to determine whether the continuous or categorical variation in the number of parties in a government or its majority or minority status in the parliament influenced the likelihood of conflict initiation or escalation. Exceptions such as Palmer et al. (2004) have also tested the effect of the pivotal parties in a 
government as well as its overall ideological orientation on the probability of conflict involvement and escalation.

The more recent quantitative literature on coalition foreign policy has challenged these studies on two fronts. First, there is a difference in the framing of research puzzles. The central motivation of the first generation studies was to solve the key puzzle in International Relations'what causes war?' - by utilising the institutional explanations of the Democratic Peace framework. In other words, these studies were not so much interested in understanding the theoretical reasons why certain domestic political factors in a democracy constrain its international behaviour as they were in which of those factors, if any, had any effect on the conflict propensity of this regime type. Categorical variables such as coalition or majority status of the government, or continuous variables such as the number of parties in government or the seat share of the government in the parliament were included in the models to scrutinise the democratic regimes to illustrate the explanatory power of the Democratic Peace theory rather than identifying the institutional constraints that they exert on a government's international interactions more broadly. Having remained by and large under the shadow of the second-image school in IR, the first generation studies have also resulted in inconclusive findings. While some of them observe that coalitions lead to a decrease in the likelihood of conflict involvement (Palmer et al., 2004), others find no relationship between the number of parties in a democratic government and its international conflict behaviour (Leblang and Chan, 2003; Reiter and Tillman, 2002).

Coalition foreign policy scholars have taken this set of findings as a starting point for attempting to theorise why we might see variation between the international behaviour of coalitions and single-party governments. What is it about the nature of a coalition government 
that differentiates its international behaviour from a single-party government? Do coalitions act more constrained than single-party governments because the former includes several veto players (Hagan, 1993; Tsebelis, 1999), or are they less constrained since the coalition partners can blame each other for policy failures and diffuse responsibility (Fisher and Hobolt, 2010)? Similarly, what explains the variation in the behaviour of majority and minority coalitions in parliamentary democracies? Kaarbo and Beasley (2008) are the first to ask these questions from the perspective of Foreign Policy Analysis, with an interest in the domestic institutional dynamics of foreign policy-making in parliamentary systems, situating their work outside the Democratic Peace debate. Their study found that coalitions, compared to single-party governments, were neither more aggressive nor more cooperative, but were instead more extreme in their foreign policy behaviours. More recent research (Clare, 2010; Beasley and Kaarbo, 2014; Oktay, 2014; OktayKaragul, 2014) have scrutinised coalitions even further to capture the structural variation among them. As we discuss below, these studies problematised the categorical understanding of coalitions and argued that the way they are set up arithmetically and ideologically should influence their international behaviour.

The second, equally important, point of divergence between the first generation studies and the coalition foreign policy literature is the scope of international behaviour that is utilised for empirical analysis. As mention above, the earlier studies have focused exclusively on international conflict: what are the domestic political causes of conflict involvement and escalation? While their interest in conflict is not surprising given the core theoretical motivations, it is severely limited relative to the wide range of behaviours of interest to foreign policy scholars. Indeed, international conflict captures a small fraction of all state interactions. Moreover, there are reasons to believe that the institutional configurations of governments may 
be altered or may matter in different ways when they are dealing with militarised conflicts, as the locus of decision-making may become restricted, international factors may become more influential, or the processes of deliberation and negotiation may be affected by the short time often associated with crises (Hermann, 1963; Hermann, 2001).

Using conflict data to explain the effects of government structure in parliamentary systems thus not only limits the universe of behaviours, but may also under-represent the impact of institutional structures on other types of foreign policy behaviours. Coalition foreign policy scholars have therefore moved away from the more traditional datasets such as the Military Interstate Disputes (Ghosn, Palmer and Bremer, 2004) to international events datasets such as the WEIS (McClelland, 1978; see Kaarbo and Beasley, 2008; Beasley and Kaarbo, 2014) and the 10 Million International Dyadic Events Dataset (10MIDE) (King and Lowe, 2004; see Oktay, 2014) to capture the broad range of activities that parliamentary governments engage in abroad. This has resulted in a more comprehensive understanding of states' international behaviour and truly moved us to the broader scope of Foreign Policy Analysis.

\section{COOPERATIVE, CONFLICTUAL, EXTREME OR COMMITTED? THE NATURE OF FOREIGN POLICY BEHAVIOUR IN COALITIONS:}

The breadth of behaviours in the events datasets has allowed coalition foreign policy scholars to develop a variety of dependent variables. Indeed, these datasets (e.g. WEIS; 10MIDE) provide a wide range of categories into which states' behaviours are classified. In an effort to quantify these for use in statistical analysis, coalitions studies have relied on the use of Goldstein's (1992) 20-point scale which arrays behaviours along a single continuum ranging from most conflictual $(-10)$ to most cooperative $(+10)$. Starting from this measure of cooperation/conflict, Beasley and 
Kaarbo (2014; Kaarbo and Beasley, 2008) fold the scale at 0 in order to produce a measure of 'extremity', where the event behaviours towards either end of the continuum involve more extreme behaviours (eg. expel, reward) while those closer to 0 involve less extreme behaviours (eg. comment, denial). Beasley and Kaarbo also develop a separate binary measure (moderately positively correlated with 'extremity') of 'commitment' by coding each event as either verbal or non-verbal.

These measures of the dependent variable have also generated debate regarding the nature of the explanandum. Oktay-Karagul (2014) argues that the dimensions of behaviourcooperative, conflictual, and extreme-assume different meanings relative to the target of the behaviour as well as to the political context within which it takes place. For instance, a government's 'political support for war' could be understood on the one hand as 'cooperative' behaviour if its target is an ally and it takes place within the context of a war coalition towards a common adversary. On the other hand, the adversary would interpret this behaviour as a form of aggression towards itself, which illustrates the relational nature of 'cooperation.' 'Extremity' is similarly context-bound. The 2000 visit of the Belgian Prime Minister to the Democratic Republic of Congo (DRC) - the first official visit to the former colony in a decade - could be framed as 'extreme' within the context of the relations between these states (Kelly, 2007: 75). Once it is decontextualised, however, the behaviour remains a modest expression of the intention that the coalition government in Belgium had to improve the relations with the DRC.

Oktay (2014), while using the same folded scale, has thus offered to re-conceptualise the dependent variable as commitment intensity, which measures the level of "the resources used and the expectations generated by the behavior" (Callahan, 1982: 183), regardless of its policy direction-cooperative or conflictual. The multilevel regression tests that use this variable 
conclude that coalitions lead to a decrease in commitment intensity compared to single-party governments (Oktay, 2014: 872). Put differently, coalitions engage in foreign policy behaviours that utilise fewer resources than single-party governments. Coalitions are also more cautious to verbally bind themselves to future policy positions when compared to their single-party counterparts.

These dependent variables have effectively moved analyses away from conflict data and towards a more nuanced and diverse set of behaviours along dimensions of interest to foreign policy scholars. While the Goldstein scale itself, however, remains rooted in more traditional 'conflict-cooperation' thinking, we have been able to conceptualise this scale in ways more sensible from the vantage point of Foreign Policy Analysis. Still there is room to explore additional measures that so far have not been examined in the extant quantitative work. An alternative measure, for example, could be to examine the degree of foreign policy variation and change we see from coalition governments compared to other types of governments. Are coalitions (or different types of coalitions) prone to a high degree of foreign policy change within governments? This would potentially capture an important expectation from coalitions that they are prone to political compromise and may by necessity engage in issue linkages and political logrolling. Drawing upon measure of variance rather than measures of means makes sense from a theoretical point of view, then, and is certainly possible with existing data.

As the preceding discussion shows, the use of events data has facilitated the development of several alternatives to conflict initiation or escalation as the key dependent variables. However, we reckon that the advantages of events data have not been fully exploited in the quantitative studies to date. That is, we have included non-conflict/war behaviours in our analyses in addition to conflict/war behaviours, but we have not disaggregated these from the 
conflict/war events and attempted to analyse them separately. Moving even further away from the logic of the 'conflict-cooperation' scale, we might also attempt to explore variations across different non-conflict/war event behaviours (such as, say, promising vs. denying), or to unpack the coalition dynamics associated with more specific types of non-conflict/war behaviours, such as signing an agreement or condemning others' behaviours. Explicating these variations in behaviour should advance our understanding of the nature of coalition foreign policy.

\section{CONTENT AND PROCESS: APPROACHES FOR EXPLAINING COALITION FOREIGN POLICY BEHAVIOUR}

As it moves the scope of analysis beyond the 'first generation studies' the quantitative literature on coalition foreign policy has made two major strides in studying the relationship between coalition politics and international behaviour. We categorise these contributions with respect to their focus on the content of government structure, and the processes through which these governments generate foreign policy behaviours.

\section{CONTENT: THE EFFECTS OF IDEOLOGY AND COALITION TYPE ON FOREIGN}

\section{POLICY BEHAVIOUR}

Whereas earlier studies (Kaarbo and Beasley, 2008) responded to the first generation of IR scholarship on domestic politics and international conflict as explained earlier, the more recent studies came as a reaction to their work by zooming in on the nuances among coalition governments to explain the variation in foreign policy behaviour. These nuances emanate from the two defining characteristics of all coalitions: their ideological composition and their type.

"Partisan sources of preference" (Kelly, 2007: 75) on the foreign policy choices of democratic governments have been iterated numerous times in the existing literature (Hagan et 
al., 2001; Rathbun, 2004). Kaarbo (2012: 7) has argued that "political ideology and partisanship are important and overlooked sources of policy disagreement," specifically referring to the coalitional environment. Some of the key qualitative contributions on coalition foreign policy (Kaarbo, 1996a, 1996b) have illustrated the effect of ideology on foreign policy choice by focusing on the role of the 'critical' or 'pivotal' junior partner in the coalition. These studies have shown that the disproportionate mathematical advantage of a critical junior partnerwithout which the government cannot maintain the majority in the parliament-can allow it to 'hijack' the coalition (Kaarbo, 1996b: 502). The resultant decision of the government reflects where this party is ideologically located relative to that of the government.

The first quantitative study to systematically incorporate the effect of ideology on coalition foreign policy behaviour belongs to Clare (2010), who has tested Kaarbo's (1996a, 1996b) 'hijacking' argument and concluded that in the absence of ideologically outlier parties, coalitions "act similar to single-party governments in their [conflict] initiatory propensity" (Clare, 2010: 985). Subsequently Oktay (2014) analysed the effects of the overall ideological cohesion of coalitions on their foreign policy commitments. She has found that ideologically loose coalitions engage in less intense international commitments, regardless of the presence of a pivotal junior party, suggesting that it is difficult to commit political will and material resources when coalition parties do not share ideological similarities. These studies have moved us beyond the single-party vs. coalition dichotomy towards a more nuanced understanding of the content of government structure.

Another key content variable that goes alongside ideological cohesion in coalition foreign policy concerns the arithmetic composition of the government. Coalitions come in various forms: they can be majority or minority governments based on their parliamentary seat share; they can 
include two or several parties, where one or neither junior partner is pivotal. We expect that each of these configurations exert different levels of constraints on the government, which should influence its foreign policy behaviour. In an effort to isolate these effects, the coalition foreign policy literature has taken various strategies. Beasley and Kaarbo (2014) utilise a combination of the parliamentary seat share and the number of parties in a government. They find that fewer parliamentary seats (as a percentage) is associated with more extreme and conflictual behaviours for coalitions but less extreme and conflictual behaviours for single parties, and that more coalition parties is associated with more conflictual behaviours and is non-linearly related to extremity of behaviours. On the other hand, Oktay (2014) uses categorical measures from the Comparative Politics literature, namely minority, minimum winning and surplus majority coalitions and concludes that only minority coalitions exert a statistically significant, negative effect on commitment intensity. Moreover, the interactive effect of these two content variablescoalition type and ideological cohesion-further exerts diverse effects on the commitment intensity of coalitions. For example, Oktay (2014) suggests that minority coalitions can increase the intensity of their international commitments if their ideological composition leaves the opposition fragmented.

These studies echo the conclusion that coalitions are not a homogeneous category of cases (Clare, 2010; Kaarbo, 2012). Instead, their ideological and arithmetic composition yields different sets of institutional constraints and opportunities that influence their international behaviour. Beyond institutional explanations, other promising 'content' factors include 'institutionalised ideas' (Ozkececi-Taner, 2005) and the specific area of foreign policy such as trade or European Union integration, which could influence government behaviour. One might also argue that ideological differences can be circumscribed when there is issue agreement, 
suggesting a more flexible relationship between party ideology and foreign policy behaviour than what is suggested by the studies discussed above. Such approaches might seek to include more contextually nuanced measures of ideological differences that include 'ideational congruities' that pervade particular political systems or even broader issue areas around which foreign policy expectations converge.

\section{PROCESS: TESTING THE THEORETICAL LINKAGES BETWEEN GOVERNMENT}

\section{STRUCTURE AND FOREIGN POLICY BEHAVIOUR}

Different institutional structures, of course, are often associated with different processes of decision-making. Given the nature of the diffusion of power within coalition governments, several processes have been proposed that tap into the way in which parties interact with one another, or the ways in which parties perceive their constraints and opportunities due to public scrutiny and support. In particular, research has emphasised four different processes that may be driving coalition foreign policy. Hijacking and Logrolling are both intra-coalition dynamics that focus on the way in which power is utilised between coalition partners in an effort to achieve foreign policy objectives. Diversion and Diffusion of Accountability are both executivelegislative dynamics that emphasise the power of public scrutiny, or 'clarity of responsibility' (Powell and Whitten, 1993) in shaping the foreign policy initiatives of coalitions.

Hijacking explanations pivot on the disproportionate 'veto power' (Tsebelis, 1995) of junior parties due to their capacity to bring down the government, as well as their ideological location in comparison with more moderate senior parties. Looking only at the veto potential of junior parties and leaving aside ideological composition, Beasley and Kaarbo (2014) find that the presence of such critical junior parties is associated with more cooperative, moderate, and less 
committed behaviours which calls into question notions of 'extremity' associated with the 'Hijacking' explanation. Both Clare (2010) and Oktay (2014) go further by combining vetoplayers with ideological composition of the coalition, and Oktay further disaggregates 'veto players' by testing it across the three types of coalitions mentioned earlier. She argues that the veto players explanation finds support specifically when the surplus majority coalition grows ideologically loose (Oktay, 2014: 879).

Logrolling has been proposed as an alternative process to that of veto-player threats, and could explain more extremity or commitment intensity in coalition foreign policies. Here the logic is that fragmented coalitions may opt to 'paper clip' several different initiatives through a process of political reciprocity rather than confronting the challenge of brokering a political compromise. Unfortunately this decision-making dynamic has received little distinct empirical examination in the quantitative studies to date, as Beasley and Kaarbo (2014) do not provide a measure to distinguish it from veto-player explanations and it is not directly considered by either Clare (2010) or Oktay (2014). Given that logrolling turns on the highly fragmented nature of some coalitions, and given the apparent importance of coalition fragility (Oktay, 2014: 863; see also Auerswald, 1999: 477), this is perhaps an area deserving of additional empirical attention.

The 'clarity of responsibility' argument, which entails both 'diversion' and 'diffusion' explanations, seems to rest primarily on the ability of parties to effectively avoid blame for bad outcomes associated with riskier policies. This assumes a general risk aversion among political parties to begin with, such that when they can be directly held to account they are more likely to err on the side of caution. This has generally been examined empirically by measuring the number of parties within a coalition or by categorising the cases where the coalition is cushioned with extra parties against blackmail by a pivotal junior party (Oktay, 2014). The reasoning here 
is that the larger the number of parties in a coalition, or where it includes more parties than necessary to maintain a majority, the lower the ability to assign blame to any one party by voters and thus the more risk-prone (committed, intense, extreme) the behaviours. Flipping this assumption, however, has the counter-intuitive effect of suggesting that coalitions may fail to gain credit for high profile initiatives, and thus we should expect them to be less risk-prone (committed, intense, extreme) than single parties. As a result, we have yet to conclusively show whether the clarity of responsibility mechanism constrains extremity or commitment in coalition foreign policy or provides opportunities for it.

Another factor that does not have a distinct decision-making explanation is the parliamentary strength of coalitions. While Beasley and Kaarbo (2014) find that weaker coalitions appear to be more extreme in their foreign policy behaviours than stronger coalitions (and the reverse holds for single party governments), it is not clear whether this is somehow related to veto-player threats, or perhaps a diversionary logic where there is excessive agreement driven by the need to divert attention from domestic weakness, or possibly some other process entirely. Clearly parliamentary strength plays a role in the stability and longevity of coalitions, but further research is needed to determine the way in which this factor influences foreign policy decision making dynamics..

\section{AVENUES FOR FUTURE RESEARCH}

Throughout this review we have highlighted fairly specific ways in which research on coalition foreign policy might advance, but there is also room for some broader reflection on the direction of coalition foreign policy research. Indeed, if we are to generate a cogent and constructive research program, we suggest that coalition foreign policy scholars should work to 
integrate findings across different methods in an effort to systematically build toward contextually sensitive process theories that help explain coalition decision-making, and that we should also further broaden our scope of investigation.

The preceding discussion has observed that the content of coalition governments and the processes with which they make policies suggests the importance of context in coalition foreign policy literature. While some of the existing quantitative studies offer methodological novelties to account for contextual variation (Oktay, 2014), we argue that coalition foreign policy should also exploit the advantages of multi-method approaches. The existing large- $\mathrm{N}$ statistical analyses of coalitions have put forward some plausible theoretical explanations for their empirical findings, but case study research would more effectively isolate the underlying mechanisms involved, highlight important contextual factors, and could help to trace the process of decision-making (Beach and Pedersen, 2013). Given the wealth of decision-making theories within FPA, this certainly seems to be an appropriate direction for further research. What is the best way forward, then, as we seek to coordinate research efforts spanning quantitative analysis and case study research? Two approaches seem promising.

First, scholarship could attempt to examine in greater detail the mechanisms purportedly involved in shaping the decision-making dynamics within coalition governments by drawing random samples (or stratified random samples) of cases from the large datasets in order to more closely examine how policies were created and whether the presumed causal mechanisms were operating as predicted (Fearon and Laitin, 2015). The random sampling approach would maximise our confidence that the larger statistical effects are not built upon an ecological fallacy wherein attributes of the units are incorrectly inferred from characteristics observed in the aggregate. While defining an appropriate universe of cases will undoubtedly pose some 
challenges, such an undertaking would work to consolidate findings across methods and would facilitate theory development and more micro levels of analysis.

Second, researchers could explicitly design comparative case studies to leverage the various independent (coalition type, size, parliamentary support, etc.) and dependent variables of interest. While a number of scholars have explored individual cases of coalition dynamics (e.g. Ozkececi-Taner, 2005; Oktay-Karagul, 2014), several others (e.g. Hagan, 1993; Kaarbo, 1996a, 1996b, 2012) have effectively utilised the comparative case study approach. As these works were striving to establish the importance of coalitions in shaping foreign policy, their case selection criteria tended to revolve around instances where coalitions did have a discernible and important effect (Hagan, 1993) or tried to compare more and less effective instances of junior party influence attempts (Kaarbo, 1996a, 1996b). These studies have helped to shape subsequent quantitative analyses, but the reverse could also be true. Drawing on the findings of quantitative studies, we suggest that future work might seek to compare coalitions involved in more commitment-intensive or extreme foreign policy behaviours with those engaged in more moderate rhetorical acts. If appropriate control/case selection variables are also drawn from existing empirical findings (number of parties, parliamentary support, etc.) we could begin to further trace the process of coalition dynamics in both a theoretically and empirically informed way.

Beyond integrating methods with the goal of contextual nuance and decision process tracing, we should also consider further broadening the scope of coalition studies and drawing upon a wider range of foreign policy questions. We have already broadened our focus by having moved the dependent variable away from war and conflict, but this can also open the door for more extensive examinations of such things as strategic diplomacy. This would reverse the focus 
on foreign policy emanating from coalitions and instead take coalitions as a potentially distinct target of other states' foreign policies. Are there systematic differences in the ways governments deal with coalition governments? Do they explicitly attempt to exploit the divided domestic power inherent within coalitions? Along these lines, what are the prevailing domestic models of foreign coalitions? A particularly promising intersection, we think, would be an examination of coalitions from an image theory perspective, given image theory's emphasis on perceptions of other governments' decision making structure (Herrmann, 2013). While the impact of institutional structure on dyadic interactions has been dominated by studies focused on 'Democratic Peace', we see real promise in approaches that seek to clarify how a target's institutional configuration might factor into a state's foreign policy strategy. Recently, Clare (2014) has demonstrated how democratic governments use their ideological composition to shape the international negotiation behaviour of their opponents. The path that the coalition foreign policy literature paves can push these inquiries toward the 'two-level games' (Putnam, 1988) framework, where we can begin to investigate whether and how the negotiating actors factor in each other's government structure to influence their win-sets.

An even more ambitious approach might attempt to bridge the constructivist turn in Foreign Policy Analysis with the 'soft positivism' associated with much foreign policy scholarship (Houghton, 2007; Kubalkova, 2001). This departs somewhat from the quantitative studies we have reviewed, but those findings can perhaps influence the types of questions that a constructivist approach might consider. For example, the degree to which a coalition is constrained-which itself seems to be a central issue for quantitative studies-may well relate to the way in which coalitions themselves are constructed within a given political context. The normative context and political meaning attached to the existence of a coalition is almost 
certainly related to the ways in which it can exploit political will to enact policies. A new coalition in Germany or Israel, for example, will be construed differently than one in the United Kingdom or other political systems with little experience with coalitional governance. The coconstitution of governed and government, then, will shape identity and construct the expectations about both representation and efficacy.

Finally, we envision a narrowing of the gap between Foreign Policy Analysis and Comparative Politics that concerns the quality of coalition policy-making. This puzzle has received significant attention in the Comparative Politics literature, where research has looked at the effect of multiparty governments on issues ranging from corruption levels (Tavits 2007), redistributive policies (Iversen and Soskice, 2006), healthcare spending (Huber, 1998) and labor law production (Tsebelis, 1999) to the order in which bills are introduced in the parliament (Martin, 2004). Whether similar hypotheses can be developed to test the quality of foreign policy-making in coalitions remains to be seen: do all coalitions spend more on defense — a likely outcome of logrolling dynamics — or do spending levels depend on the coalition's ideological composition? Are coalitions slow to respond to international crises relative to single-party governments, and if so, why? Moving forward, quantitative designs to study these questions among others will expand our understanding of coalitions and bring this research program closer to its counterparts in other subfields. 


\section{BIBLIOGRAPHY}

Auerswald, D.P. (1999) 'Inward bound: Domestic institutions and military conflicts', International Organization 53(3): 469-504.

Beach, D. and Pedersen, R. B. (2013) Process-Tracing Method: Foundations and Guidelines, Ann Arbor: University of Michigan Press.

Beasley, R.K. and Kaarbo, J. (2014) 'Explaining Extremity in the Foreign Policies of Parliamentary Democracies', International Studies Quarterly 58(4): 729-740.

Callahan, P. (1982). 'Commitment', in P. Callahan, L.P. Brady and M.G. Hermann (eds.) Describing Foreign Policy Behavior, Beverly Hills, CA: Sage, pp. 177-206.

Clare, J. (2010) 'Ideological Fractionalization and the International Conflict Behavior of Parliamentary Democracies', International Studies Quarterly 54(4): 965-987.

Clare, J. (2014) 'Hawks, Doves, and International Cooperation', Journal of Conflict Resolution 58(7): 1311-1337.

Fearon, J.D. and Laitin, D.D. (2015) 'Integrating Qualitative and Quantitative Methods', unpublished manuscript.

Fisher, S.D. and Hobolt, S.B. (2010) 'Coalition government and electoral accountability', Electoral Studies 29(3): 358-369.

Gallagher, M., Laver. M. and Mair, P. (2006) Representative Government in Modern Europe (3rd Ed.), Boston: McGraw Hill.

Ghosn, F., Palmer, G., and Bremer, S.A. (2004) 'The MID3 data set, 1993-2001: Procedures, coding rules, and description', Conflict Management and Peace Science 21(2): 133-154.

Goldstein, J.S. (1992) 'A conflict-cooperation scale for WEIS events data', Journal of Conflict Resolution 36(2): 369-385.

Hagan, J.D. (1993) Political Opposition and Foreign Policy in Comparative Perspective, Boulder, CO: Lynne Rienner.

Hagan, J., Everts, P.P., Fukui, H. and Stempel, J.D. (2001) 'Foreign Policy By Coalition.

Deadlock, Compromise, and Anarchy', International Studies Review 3(2): 169-216.

Hermann, C.F. (1963) 'Some Consequences of Crisis Which Limit the Viability of Organizations', Administrative Science Quarterly 1: 61-82

Hermann, M. (2001) 'How Decision Units Shape Foreign Policy: A Theoretical Framework,' International Studies Review 3(2): 47-81. 
Herrmann, R. K. (2013). Perceptions and image theory in international relations. In L. Huddy, D. O. Sears, J. S. Levy, L. Huddy, D. O. Sears, J. S. Levy (Eds.), The Oxford handbook of political psychology (2nd ed.) (pp. 334-363). New York, NY, US: Oxford University Press.

Houghton, D.P. (2007) 'Reinvigorating the Study of Foreign Policy Decision Making: Toward a Constructivist Approach', Foreign Policy Analysis, 3(1): 24-45.

Huber, J. D. (1998) 'How Does Cabinet Instability Affect Political Performance? Portfolio Volatility and Health Care Cost Containment in Parliamentary Democracies', American Political Science Review, 92(3): 577-591.

Hudson, V.M. and Vore, C.S. (1995) 'Foreign policy analysis yesterday, today, and tomorrow', Mershon International Studies Review 39(2): 209-238.

Ireland, M.J. and Gartner, S.S. (2001) 'Time to Fight Government Type and Conflict Initiation in Parliamentary Systems', Journal of Conflict Resolution 45(5): 547-568.

Iversen, T. and Soskice, D. (2006) 'Electoral Institutions and the Politics of Coalitions: Why Some Democracies Redistribute More than Others', American Political Science Review 100(2): $165-181$.

Kaarbo, J. (1996a) 'Influencing Peace Junior Partners in Israeli Coalition Cabinets', Cooperation and Conflict 31(3): 243-284.

Kaarbo, J. (1996b) 'Power and influence in foreign policy decision making: The role of junior coalition partners in German and Israeli foreign policy', International Studies Quarterly 40(4): 501-530.

Kaarbo, J. and Beasley, R.K. (2008) 'Taking It to the Extreme: The Effect of Coalition Cabinets on Foreign Policy’, Foreign Policy Analysis 4(1): 67-81.

Kaarbo, J. (2012) Coalition Politics and Cabinet Decision Making: A Comparative Analysis of Foreign Policy Choices, Ann Arbor: University of Michigan Press.

Kelly, C. (2007) 'Belgian Intervention Policy in the DRC: Causes and Consequences of the Reorientation, 1999-2006', Les Cahiers du RMES 4(2): 59-106.

King, G. and Lowe, W. (2003) 'An automated information extraction tool for international conflict data with performance as good as human coders: A rare events evaluation design', International Organization 57(3): 617-642.

Kubálková, V. (Ed.). (2001) Foreign policy in a constructed world (Vol. 4), ME Sharpe.

Leblang, D. and Chan, S. (2003) 'Explaining Wars Fought by Established Democracies: Do Institutional Constraints Matter?' Political Research Quarterly 56(4): 385-400. 
Leeds, B.A. and Davis, D.R. (1997) 'Domestic political vulnerability and international disputes', Journal of Conflict Resolution 41(6): 814-834.

Leeds, B.A. and Davis, D.R. (1999) 'Beneath the surface: Regime type and international interaction, 1953-78', Journal of Peace Research 36(1): 5-21.

Martin, L. W. (2004) 'The Government Agenda in Parliamentary Democracies', American Journal of Political Science, 48(3): 445-461.

McClelland, C.A. (1978) World Event/interaction Survey (WEIS), 1966-1978, Ann Arbor: Interuniversity Consortium for Political and Social Research.

Oktay, S. (2014) 'Constraining or enabling? The effects of government composition on international commitments', Journal of European Public Policy 21(6): 860-884.

Oktay-Karagul, S. (2014) 'Unpacking Coalitions: Explaining International Commitment in European Governments', Ph.D. dissertation, Department of Political Science, Syracuse University.

Ozkececi-Taner, B. (2005). 'The Impact of Institutionalized Ideas in Coalition Foreign Policy Making: Turkey as an Example, 1991-2002', Foreign Policy Analysis, 1(3), 249-278.

Palmer, G., London, T. and Regan, P. (2004) 'What's stopping you? The sources of political constraints on international conflict behavior in parliamentary democracies', International Interactions 30(1): 1-24.

Powell, G.B. and Whitten, G.D. (1993) 'A cross-national analysis of economic voting: taking account of the political context', American Journal of Political Science 37(2): 391-414.

Prins, B.C. and Sprecher, C. (1999) 'Institutional constraints, political opposition, and interstate dispute escalation: Evidence from parliamentary systems, 1946-89', Journal of Peace Research 36(3): 271-287.

Putnam, R.D. (1988) 'Diplomacy and Domestic Politics: The Logic of Two-Level Games', International Organization 42(3): 427-460.

Rathbun, B. (2004) Partisan Interventions: European Party Politics and Peace Enforcement in the Balkans, New York: Cornell University Press.

Reiter, D. and Tillman, E.R. (2002) 'Public, legislative, and executive constraints on the democratic initiation of conflict', Journal of Politics 64(3): 810-826.

Schuster, J. and Maier, H. (2006) 'The Rift: Explaining Europe's Divergent Iraq Policies in the Run-Up of the American-Led War on Iraq', Foreign Policy Analysis 2(3): 223-244. 
Tavits, M. (2007). 'Clarity of Responsibility and Corruption', American Journal of Political Science, 51(1): 218-229.

Tsebelis, G. (1995) 'Decision making in political systems: Veto players in presidentialism, parliamentarism, multicameralism and multipartyism', British Journal of Political Science 25(3): 289-325.

Tsebelis, G. (1999) 'Veto players and law production in parliamentary democracies: An empirical analysis', American Political Science Review 93(3): 591-608. 